\title{
Men with cancer change their health behaviour: a prospective study from the Danish Diet, Cancer and Health Study
}

\author{
RV Karlsen ", , PE Bidstrup', J Christensen², SB Larsen', A Tjønneland ${ }^{3}$, SO Dalton' and C Johansen' \\ 'Survivorship, Danish Cancer Society Research Centre, Strandboulevarden 49, Copenhagen 2100, Denmark; 'Biostatistics and Bioinformatics, Danish \\ Cancer Society Research Centre, Copenhagen, Denmark; ${ }^{3}$ Diet, Genes and Environment, Danish Cancer Society Research Centre, Copenhagen, Denmark
}

BACKGROUND: Health behaviour changes may improve the quality of life and survival among cancer survivors. We prospectively examined changes in health behaviour among and between men with prostate cancer (PC), men with cancers other than PC and cancer-free men.

METHODS: We analysed data for 20914 men (50-65 years), 426 with cancer, and 20488 persons who were cancer-free between baseline (1993-1997) and follow-up (2000-2002) in multiple linear regression models to determine differences in changes in body mass index (BMI) and in alcohol and tobacco consumption.

RESULTS Body mass index and tobacco and alcohol consumption decreased significantly $(P<0.00 \mathrm{I})$ between baseline and follow-up among both men with cancer and cancer-free men. Men with cancers other than PC significantly decreased their BMI $(\beta=-058$; 95\% confidence interval $(\mathrm{Cl}):-0.77,-0.40)$ and tobacco consumption $(\beta=-1.36 ; 95 \% \mathrm{Cl}:-2.22,-0.49)$ compared with cancer-free men and were significantly more likely to quit smoking and lose weight.

CONCLUSION: Men with cancers other than PC decreased their tobacco consumption and BMI significantly more than cancer-free men. Men with cancer do change their health behaviour; clinicians should take this into account in planning follow-up care for cancer survivors.

British Journal of Cancer (2012) 1 07, 20I-206. doi:I0.1038/bjc.20I2.238 www.bjcancer.com

Published online 29 May 2012

(C) 2012 Cancer Research UK

Keywords: health behaviour; lifestyle; men

Behaviour such as smoking, alcohol consumption, physical inactivity and high body mass index (BMI) are associated with increased risks for cancer (Demark-Wahnefried et al, 2008; Khan et al, 2010). The increasing number of cancer survivors $(\sim 11.4$ million persons with a history of cancer were alive in the United States in 2006: American Cancer Society, 2010) has prompted studies of the effect of behaviour on both survival and also quality of life after treatment for cancer (Demark-Wahnefried et al, 2005; Blanchard et al, 2008; Demark-Wahnefried and Jones, 2008; Gritz and Demark-Wahnefried, 2009). Some studies have suggested that a cancer diagnosis may present a teachable moment for changes in health behaviour (Demark-Wahnefried et al, 2000, 2005; Pinto et al, 2000). Health behaviour can affect the risk for recurrence, second cancers and other chronic diseases, such as cardiovascular disease, diabetes and obesity (Aziz, 2002; Demark-Wahnefried et al, 2005). Furthermore, sociodemographic factors such as age, marital status and education may affect health behaviour (Demark-Wahnefried et al, 2000, 2005; Umberson et al, 2010). A clear understanding of these complex associations is needed in order to identify the changes in health behaviour that could improve the survival and quality of life of cancer patients (Aziz, 2002; Demark-Wahnefried et al, 2005; Blanchard et al, 2008; Gritz and Demark-Wahnefried, 2009).

Comparisons of the health behaviour of cancer survivors and cancer-free persons have shown only small differences in levels of

*Correspondence: RV Karlsen; E-mail: randi@cancer.dk

Received 27 January 2012; revised 16 April 2012; accepted 25 April 2012; published online 29 May 2012 smoking, physical activity, diet and BMI (Bellizzi et al, 2005; Coups and Ostroff, 2005; Eakin et al, 2007; Mayer et al, 2007). Most of these studies had, however, methodological limitations, such as a cross-sectional design, self-reported cancer diagnosis and health behaviour known to be subject to recall bias. We found only one prospective study in which the health behaviour of women with breast or colon cancer was compared with that of cancer-free women, which showed little change towards compliance with cancer prevention guidelines (Skeie et al, 2009). No studies have been conducted on health behaviour changes after a cancer diagnosis only among men, even though men engage in more risky behaviour, including smoking and drinking (Courtenay, 2000; Oksuzyan et al, 2008) and may be less likely to change their behaviour or to maintain any changes (Patterson et al, 2003; Demark-Wahnefried et al, 2005; Mosher et al, 2009).

We conducted a prospective study to compare differences in changes in BMI and alcohol and tobacco consumption among men with and without cancer. As different cancers and their treatment may influence health behaviour differently (Gritz et al, 1991; Ostroff et al, 1995; Demark-Wahnefried et al, 2005), we evaluated behaviour changes separately for the homogeneous group of men with prostate cancer (PC) and the combined group of men with other cancers. We hypothesised, that men with cancer would not change their health behaviour significantly compared with cancer-free men to comply with the recommendations of the Danish National Health Board (www.sst.dk) with regard to alcohol consumption (three drinks per day; one drink $=12 \mathrm{~g}$ alcohol), BMI $\left(>18.5 \mathrm{~kg} \mathrm{~m}^{-2}\right.$ $<25 \mathrm{~kg} \mathrm{~m}^{-2}$ ), and use of tobacco (non-smokers) when adjusting for age, educational and marital status as potential confounders. 


\section{MATERIALS AND METHODS}

\section{Study population}

We used data from the Diet Cancer and Health Study, for which a cohort was established prospectively to evaluate the aetiological role of diet in cancer risk. The cohort consisted of persons identified in the Civil Population Register, in which all Danish residents have been registered since 1968 and assigned a unique 10-digit personal identification number, which ensures accurate linkage with all national registries (Pedersen et al, 2006). A detailed description of the cohort has been published elsewhere (Tjonneland et al, 2007). In brief, between December 1993 and May 1997, all individuals (80 996 men and 79729 women) living in greater Copenhagen and the Aarhus area and who fulfilled the inclusion criteria were invited to participate. Baseline and followup questionnaires were sent from and returned to the Institute of Cancer Epidemiology, Department of Diet Cancer and Health. Two reminders were sent at both assessment times to non-responders. Participants went to one of the two study centres (in Copenhagen and Aarhus), where trained professionals measured their height and weight and calculated their BMI at baseline. The invitation was accepted by 57053 persons, of whom 27179 were men $(33.5 \%$ of those invited), and all the participants filled in a self-administered baseline questionnaire eliciting information on sociodemographic factors and health behaviour. In 2000-2002, a follow-up survey of all 54379 eligible cohort participants was conducted, and 45298 (83.3\% of those responding at baseline) filled in a follow-up questionnaire; of these, 21071 were men. Participants for whom information on health behaviour was missing were excluded from the relevant analysis.

\section{Information on cancer status}

Since 1943, all cases of cancer in Denmark have been registered in the Danish Cancer Registry and classified according to a modified Danish version of the International Classification of Disease, 7th revision (Storm et al, 1997). By linkage with the Danish Cancer Registry, we identified 453 men who had received a diagnosis of cancer (excluding non-melanoma skin cancer) in the period between baseline and follow-up. Men with secondary or unspecified cancers $(n=25)$ and men for whom information on education and marital status was missing $(n=132)$ were excluded, leaving 20914 men, of whom 426 received a diagnosis of cancer: head and neck $(n=37)$, upper gastrointestinal $(n=21)$, lung $(n=20)$, malignant melanoma $(n=51)$, prostate $(n=129)$, colorectal $(n=82)$, urinary and bladder $(n=29)$, leukaemia or lymphoma $(n=28)$ and other $(n=29)$.

\section{Information on education and marital status}

Information on educational status (basic or high school, vocational training and higher education) was obtained from the baseline questionnaire. Information on marital status at baseline (never married, divorced or widowed, married or with a registered partner) and vital status (alive or dead) was obtained from the Civil Population Register.

\section{Information on health behaviour}

At both baseline and follow-up, participants were asked to indicate how much they smoked per day in terms of cigarettes ( $1 \mathrm{~g}$ tobacco/ cigarette), cigars ( $4.5 \mathrm{~g}$ tobacco/cigar), cheroots $(3 \mathrm{~g}$ tobacco/ cheroot) and pipes ( $3 \mathrm{~g}$ tobacco/pipe), and these were summed as grams of tobacco per day. Alcohol was also measured as grams per day, one drink corresponding to $12 \mathrm{~g}$ of alcohol. At baseline, participants were asked to indicate how often and how much they drank of each of the following types of alcohol: light beer
(8.9 $\mathrm{g}$ alcohol/bottle), ordinary beer (12.2 $\mathrm{g}$ alcohol/bottle), strong beer (17.5 g alcohol/bottle), wine ( $12.2 \mathrm{~g}$ alcohol/glass), fortified wine (9.3 g alcohol/unit) and liquor (9.9 g alcohol/unit). The following categories were used: never, $<1$ per month, 1 per month, 2-3 per month, 1 per week, $2-4$ per week, 5-6 per week, 1 per day, $2-3$ per day, $4-5$ per day, $6-7$ per day, $\geqslant 8$ per day. At follow-up, separate items were included for red wine $v s$ white and rosé wine, and the categories were slightly different: never or rarely, 1 per month, 2-3 per month, 1-2 per week, 3-4 per week, 5-6 per week, 1 per day, $2-3$ per day, $4-5$ per day, $6-7$ per day, $\geqslant 8$ per day. The baseline alcohol consumption categories 'never' and ' $<1$ per month' were combined for the analyses. We used BMI as an indicator of overweight and the underlying health behaviour with regard to a balanced calorie intake and physical activity. At baseline, weight and height were measured by trained professionals, and BMI was calculated as (weight $(\mathrm{kg}) /\left(\right.$ height $\left.(\mathrm{m})^{2}\right)$. At follow-up, weight was self-reported.

\section{Statistical analysis}

Descriptive analyses were conducted of demographic factors, mean tobacco and alcohol consumption and BMI at baseline and follow-up for men with cancers other than PC, men with PC and cancer-free men. $\chi^{2}$ tests were used to test the difference in health behaviour changes (categorical) between baseline and follow-up. Multiple linear regression models with $95 \%$ confidence intervals (CIs) were used to examine differences in health behaviour changes (BMI, tobacco and alcohol consumption as continuous variables) from baseline to follow-up between men with cancers other than PC and cancer-free men and between men with PC and cancer-free men. The analyses included adjustment for age at baseline and baseline values for the health behaviour in question.

As the estimates of differences in smoking, alcohol intake and BMI did not follow a normal distribution, we conducted nonparametric analyses (Wilcoxon). The results varied only minimally from those of the parametric tests, and we present here only the results of the parametric tests, which allow precise estimates of differences.

Separate analyses were conducted for men with a diagnosis less than and more than 2 years before the follow-up measurement. Separate analyses in multiple logistic regression models were also conducted for men who quit smoking, decreased their BMI from overweight $\left(\geqslant 25 \mathrm{~kg} \mathrm{~m}^{-2}\right)$ to normal $\left(<25 \mathrm{~kg} \mathrm{~m}^{-2}\right)$ or decreased their alcohol consumption from $>3$ to $<3$ drinks per day between baseline and follow-up.

The GLM and Genmod procedure in the SAS statistical software package release 9.1 (SAS Institute, Inc., Cary, NC, USA) was used for the statistical analyses.

\section{RESULTS}

The mean age of the 20914 men at entry into the study was 56.6 years (range, 50.1-65.6 years). The mean ages of men with cancers other than PC and men with PC were slightly higher than that of cancer-free men (58.2 vs 59.6 vs 56.5) (Table 1). More cancer-free men than men with cancers other than PC had higher education ( $25 \%$ vs $21 \%$ ), while no group differences were seen with regard to marital status. Among men with cancers other than PC, $44 \%$ were current smokers, $36 \%$ took more than three drinks a day $(36 \mathrm{~g}$ alcohol) and $62 \%$ were overweight $(B M I \geqslant 25)$ at baseline. Tobacco and alcohol consumption and BMI decreased significantly between baseline and follow-up in all three groups (Table 1).

Men with cancers other than PC decreased their tobacco consumption $(\beta=-1.36 \mathrm{~g}$ per day; $95 \% \mathrm{CI}:-2.22,-0.49)$ and BMI $\left(\beta=-0.58 \mathrm{~kg} \mathrm{~m}^{-2} ; 95 \%\right.$ CI: $\left.-0.77,-0.40\right)$ significantly more than the cancer-free men, whereas men with PC had a small 
Table I Demographic characteristics and comparison of health behaviours within groups at baseline and follow-up according to cancer status among 20 914 Danish men in the Diet, Cancer and Health Study

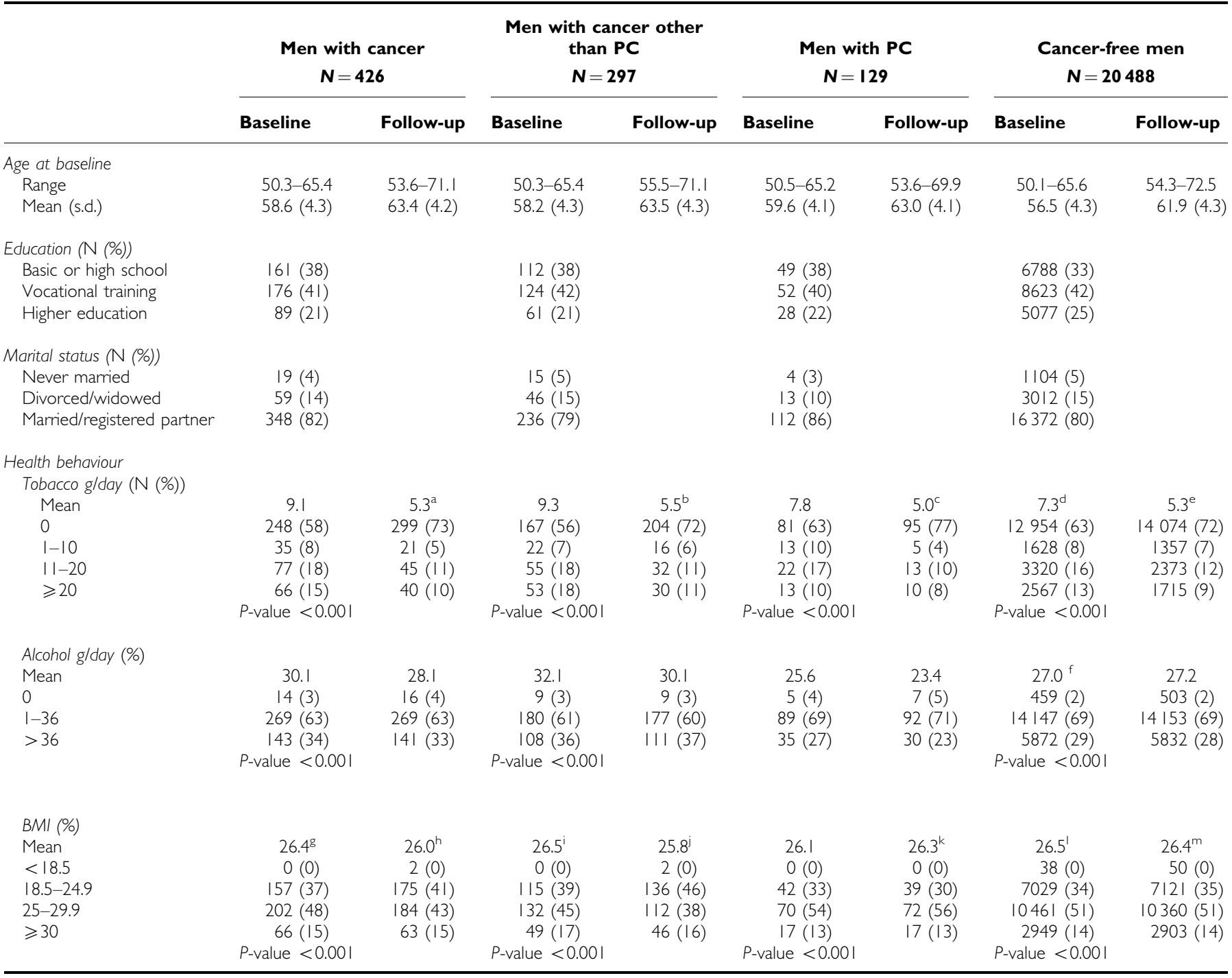

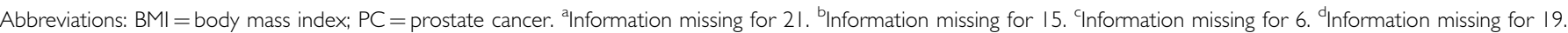
eInformation missing for 969. Information missing for 10. IInformation missing for 1. ' Information missing for 2. Information missing for I. Information missing for 2. ${ }^{\mathrm{k}}$ Information missing for 1. 'Information missing for 11. ' Information missing for 54. All numbers, proportions and means for baseline and follow-up are based on people with no missing information at either time.

but significant increase in BMI $\left(\beta=0.28 \mathrm{~kg} \mathrm{~m}^{-2} ; 95 \% \mathrm{CI}: 0.00\right.$, $0.55)$ as compared with cancer-free men (Table 2).

Among men who were smokers at baseline, men with cancers other than PC were significantly more likely to quit smoking than cancer-free men. Thus, $59 \%$ of smokers with cancers other than PC and $31 \%$ of cancer-free smokers quit smoking. Among men who were overweight at baseline, men with cancers other than PC were significantly more likely to decrease their BMI to normal than were cancer-free men, with a change in $13 \%$ of men with cancers other than PC and $7 \%$ in cancer-free men. Men with cancers other than PC who took more than three drinks per day at baseline were significantly less likely to decrease their alcohol consumption than cancer-free men (Table 3).

The mean time since diagnosis was 2.2 years (range, $0.01-5.51$ ) for men with cancers other than PC and 2.0 years (range, 0.01-5.29) for those with PC. Among men who received their diagnosis within 2 years of follow-up, those with cancers other than PC had decreased their BMI $\left(\beta=-0.89 \mathrm{~kg} \mathrm{~m}^{-2} ; 95 \% \mathrm{CI}\right.$ : $-1.14,-0.63)$ and tobacco use $(\beta=-1.32 \mathrm{~g}$ per day; $95 \% \mathrm{CI}$ :
$-2.52,-0.12)$, but not their alcohol consumption, significantly more than cancer-free men. Men with cancers other than PC diagnosed $>2$ years before the follow-up measurement had decreased their tobacco consumption significantly more than cancer-free men ( $\beta=-1.41 \mathrm{~g}$ per day; $95 \% \mathrm{CI}$ : $-2.65,-0.17)$, but not their alcohol consumption or BMI (data not shown).

\section{DISCUSSION}

Men irrespective of a cancer diagnosis, over time changed their health behaviour to comply with the recommendations of the Danish National Board of Health. Positive changes in regard to smoking and BMI appeared to be confined to the group of men with cancers other than PC, who were more likely to quit smoking and lose weight. We found no significant difference in positive health behaviour changes between men with PC and cancer-free men.

These findings confirm the assumption that cancer and its treatment influence health behaviour differently. Treatment for PC 
Table 2 Multiple linear regression models for differences in change in health behaviour among men with cancer and cancer-free, men with cancer other than PC and cancer-free men, and men with PC and cancer-free men in the Diet, Cancer and Health Study

\begin{tabular}{|c|c|c|c|c|c|c|c|c|c|}
\hline \multirow{3}{*}{ Characteristic } & \multirow{2}{*}{\multicolumn{3}{|c|}{$\begin{array}{c}\text { Men with cancer } \\
(N=426) \text { and cancer-free } \\
\text { men }(N=20488) \\
B^{\mathrm{a}}(95 \% \mathrm{Cl})\end{array}$}} & \multirow{2}{*}{\multicolumn{3}{|c|}{$\begin{array}{c}\text { Men with cancer other } \\
\text { than } P C(N=297) \text { and } \\
\text { cancer-free men }(N=20488) \\
B^{\mathrm{a}}(95 \% \mathrm{Cl})\end{array}$}} & \multirow{2}{*}{\multicolumn{3}{|c|}{$\begin{array}{c}\text { Men with PC } \\
(N=129) \text { and cancer-free } \\
\text { men }(N=20488) \\
B^{\mathrm{a}}(95 \% \mathrm{Cl})\end{array}$}} \\
\hline & & & & & & & & & \\
\hline & $\begin{array}{c}\text { Smoking } \\
\text { (g per day) }\end{array}$ & $\begin{array}{l}\text { Alcohol } \\
\text { intake } \\
\text { (g per day) }\end{array}$ & BMI $\left(\mathbf{k g ~ m}^{-2}\right)$ & $\begin{array}{c}\text { Smoking } \\
\text { (g per day) }\end{array}$ & $\begin{array}{l}\text { Alcohol } \\
\text { intake } \\
\text { (g per day) }\end{array}$ & BMI $\left(\mathbf{k g ~ m}^{-2}\right)$ & $\begin{array}{l}\text { Smoking } \\
\text { (g per day) }\end{array}$ & $\begin{array}{l}\text { Alcohol } \\
\text { intake } \\
\text { (g per day) }\end{array}$ & BMI $\left(\mathbf{k g ~ m}^{-2}\right)$ \\
\hline & & & & & & & & & \\
\hline \multicolumn{10}{|l|}{ Cancer } \\
\hline $\begin{array}{l}\text { No } \\
\text { Yes }\end{array}$ & $\begin{array}{c}\text { Reference } \\
-1.05 \\
(-1.77,-0.32)\end{array}$ & $\begin{array}{l}\text { Reference } \\
\quad \text { NS }\end{array}$ & $\begin{array}{c}\text { Reference } \\
-0.33 \\
(-0.48,-0.17)\end{array}$ & $\begin{array}{c}\text { Reference } \\
-1.36 \\
(-2.22,-0.49)\end{array}$ & $\begin{array}{l}\text { Reference } \\
\text { NS }\end{array}$ & $\begin{array}{c}\text { Reference } \\
-0.58 \\
(-0.77,-0.40)\end{array}$ & $\begin{array}{l}\text { Reference } \\
\text { NS }\end{array}$ & $\begin{array}{l}\text { Reference } \\
\text { NS }\end{array}$ & $\begin{array}{c}\text { Reference } \\
0.28 \\
(0.00,0.55)\end{array}$ \\
\hline \multicolumn{10}{|l|}{ Education } \\
\hline $\begin{array}{l}\text { Basic/high school } \\
\text { Vocational training } \\
\text { Higher education }\end{array}$ & $\begin{array}{c}\text { Reference } \\
-0.44 \\
(-0.68,-0.20) \\
-0.43 \\
(-0.70,-0.15)\end{array}$ & $\begin{array}{c}\text { Reference } \\
1.63 \\
(1.02,2.22) \\
2.82 \\
(2.13,3.51)\end{array}$ & $\begin{array}{c}\text { Reference } \\
-0.17 \\
(-0.22,-0.12) \\
-0.27 \\
(-0.33,-0.21)\end{array}$ & $\begin{array}{c}\text { Reference } \\
-0.43 \\
(-0.67,-0.18) \\
-0.42 \\
(-0.70,-0.15)\end{array}$ & $\begin{array}{c}\text { Reference } \\
1.62 \\
(1.01,2.22) \\
2.80 \\
(2.11,3.49)\end{array}$ & $\begin{array}{c}\text { Reference } \\
-0.17 \\
(-0.22,-0.12) \\
-0.27 \\
(-0.33,-0.21)\end{array}$ & $\begin{array}{c}\text { Reference } \\
-0.42 \\
(-0.66,-0.18) \\
-0.40 \\
(-0.68,-0.13)\end{array}$ & $\begin{array}{c}\text { Reference } \\
1.63 \\
(1.03,2.24) \\
2.88 \\
(2.19,3.57)\end{array}$ & $\begin{array}{c}\text { Reference } \\
-0.17 \\
(-0.22,-0.11) \\
-0.27 \\
(-0.33,-0.21)\end{array}$ \\
\hline \multicolumn{10}{|l|}{ Marital status } \\
\hline $\begin{array}{l}\text { Never married } \\
\text { Divorced/widowed }\end{array}$ & $\begin{array}{l}\text { Reference } \\
\text { NS }\end{array}$ & $\begin{array}{c}\text { Reference } \\
2.10 \\
(0.81,3.40)\end{array}$ & $\begin{array}{l}\text { Reference } \\
\text { NS }\end{array}$ & $\begin{array}{l}\text { Reference } \\
\quad \text { NS }\end{array}$ & $\begin{array}{c}\text { Reference } \\
2.07 \\
(0.77,3.04)\end{array}$ & $\begin{array}{l}\text { Reference } \\
\text { NS }\end{array}$ & $\begin{array}{l}\text { Reference } \\
\text { NS }\end{array}$ & $\begin{array}{c}\text { Reference } \\
2.14 \\
(0.83,3.44)\end{array}$ & $\begin{array}{l}\text { Reference } \\
\quad \text { NS }\end{array}$ \\
\hline With partner & NS & $\begin{array}{c}1.91 \\
(0.76,3.06)\end{array}$ & NS & $\begin{array}{c}-0.55 \\
(-1.01,-0.09)\end{array}$ & $\begin{array}{c}1.89 \\
(0.74,3.04)\end{array}$ & NS & $\begin{array}{c}-0.57 \\
(-1.03,-0.11)\end{array}$ & $\begin{array}{c}1.90 \\
(0.75,3.06)\end{array}$ & NS \\
\hline
\end{tabular}

Abbreviations: NS = non-significant; $\mathrm{BMI}=$ body mass index; $\mathrm{PC}=$ prostate cancer; $\mathrm{Cl}=$ confidence interval. Improvement indicates decreased tobacco or alcohol consumption or BMI. ${ }^{a} \beta$ Coefficients reflect the change in health behaviour for each decrement in the independent variable. Analyses are mutually adjusted and adjusted for age at baseline. Decrease in health behaviour is represented by $(-)$.

Table 3 Multiple logistic regression models of differences in health behaviour change among men with and without cancer in a subgroup of men who quit smoking, decreased alcohol consumption to $<3$ drinks per day or decreased BMI from overweight to normal weight from baseline to follow-up in the Diet, Cancer and Health Study

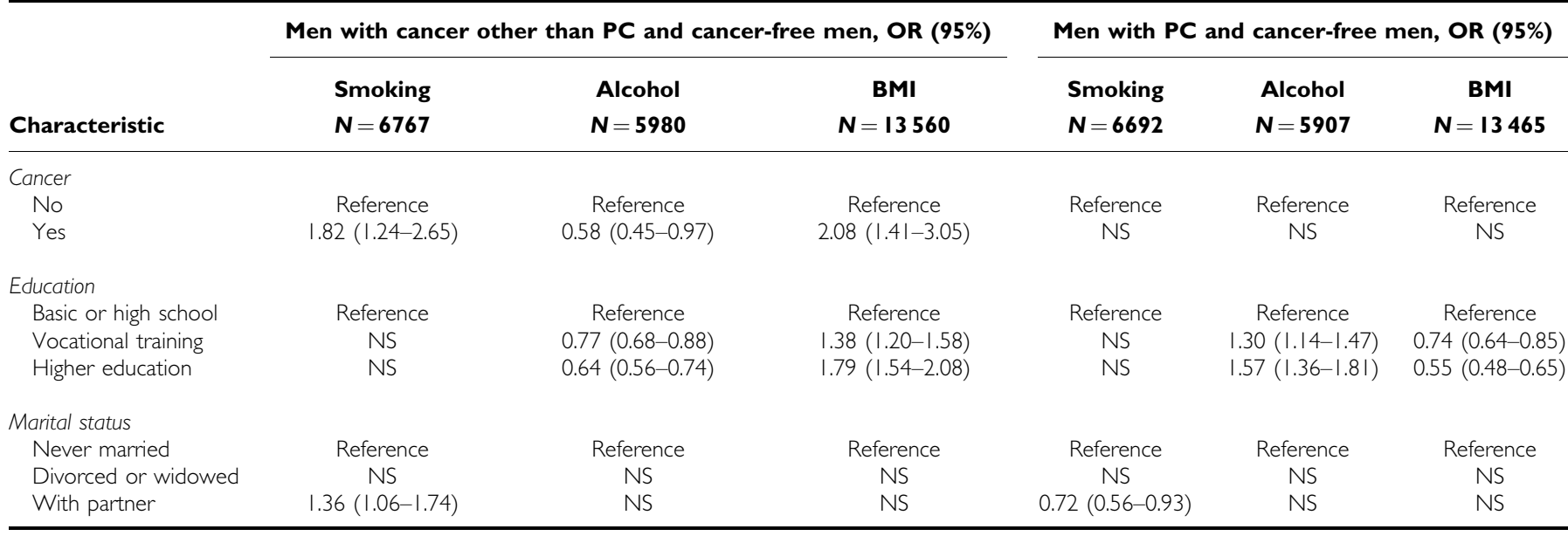

Abbreviations: $\mathrm{BMI}=$ body mass index; $\mathrm{NS}=$ non-significant; $\mathrm{OR}=$ odds ratio; $\mathrm{PC}=$ prostate cancer. Analyses are mutually adjusted and adjusted for age at baseline.

may have a less severe impact on general health and may therefore not induce changes in health behaviour. Furthermore, the change in BMI among men with cancers other than PC might have been due to progression of cancer or its treatment.

We also found positive changes in health behaviour among cancer-free men, perhaps due to national campaigns recommending changes in health behaviour associated with lifestyle diseases like cancer, diabetes and cardiovascular disease (Khan et al, 2010). Participation in the Diet Cancer and Health study might also have increased awareness about health behaviour; however, this would apply to men with and without cancer.

The results of this study are in line with those of populationbased surveys that showed only small differences in the health behaviour of cancer survivors and cancer-free persons (Bellizzi et al, 2005; Coups and Ostroff, 2005; Eakin et al, 2007; Mayer et al, 2007).
We found no significant difference in alcohol consumption between men with cancers other than PC and cancer-free men; however, men with cancers other than PC were significantly less likely to decrease their alcohol consumption from more than to fewer than three drinks a day. Also, in contrast to previous studies (Bellizzi et al, 2005; Coups and Ostroff, 2005), we found more heavy drinkers among men with cancers other than PC than among cancer-free men.

Even though we found that men with cancers other than PC significantly decreased their tobacco consumption, the number of current smokers at follow-up was similar to that among cancerfree men and in accordance with survey studies (Coups and Ostroff, 2005; Mayer et al, 2007). The baseline levels of tobacco consumption were higher in men with cancers other than PC and then decreased to levels similar to those of cancer-free men. 
We did not confirm the previous finding of a higher prevalence of overweight (BMI $\geqslant 25 \mathrm{~kg} \mathrm{~m}^{-2}$ ) among cancer patients than cancerfree persons seen in previous studies (Coups and Ostroff, 2005; Eakin et al, 2007; Mayer et al, 2007). A comparison of men with PC and cancer-free men, however, showed a significantly greater increase in BMI among men with PC. This might have been a result of hormonal therapy, with which weight gain is a well-documented adverse event (Kumar et al, 2005).

Sociodemographic factors such as educational level have been suggested to influence tobacco consumption (Rasmussen, 2005), alcohol consumption (Bjork et al, 2006) and BMI (Groth et al, 2009) in Denmark and elsewhere (Barbeau et al, 2004; McLaren et al, 2007), as also confirmed in this study. A higher educational level was associated with decreases in smoking and BMI but with an increase in alcohol consumption. The latter finding may indicate that the study population included well-educated retired persons with adequate economic resources, who have been found to consume more alcohol in Denmark (Bjork et al, 2006).

An advantage of this study is its prospective design, which minimised recall bias. We used detailed registry-based information on cancer diagnoses and on marital status for a large populationbased cohort. Furthermore, we strengthened our study by including separate analyses of a homogeneous group of men with PC and of men who quit smoking, decreased their BMI to normal weight or decreased their alcohol consumption to fewer than three drinks per day. Information on tobacco and alcohol consumption was based on self-reports; self-reported alcohol consumption accounts for $71 \%$ of sales in Denmark (Ekholm et al, 2008). The measures of alcohol consumption were slightly different in the baseline and follow-up questionnaires, which might have resulted in the reporting of more alcohol consumption at follow-up. Still, we have no reason to believe that underreporting of alcohol use would be different for men with and without cancer.

The alcohol consumption of the participants in this study was relatively high but similar to that of the general Danish population, in which the mean alcohol consumption of men increased from 1.5 to 2.1 drinks per day $(25 \mathrm{~g}$ alcohol per day) in the period 1987-2003 (Bjork et al, 2006). During the period of this study, moderate alcohol intake was considered to protect against heart disease (Broholm, 2008), which might partly explain the high alcohol consumption found.

Weight and height were measured at baseline in the study centres by trained professionals, who calculated BMI. At follow-up, weight was self-reported, which might have resulted in underestimates. This assumption was confirmed in a validation study of the Diet Cancer and Health Study, which showed that self-reported mean weight was slightly underestimated $(0.6 \mathrm{~kg})$ among the 176 male participants (Bigaard et al, 2005).

In this study, the follow-up questionnaire was completed up to 5 years after cancer diagnosis. The results of separate analyses for men whose cancers were diagnosed within 2 years of follow-up and $>2$ years before follow-up may indicate that changes in tobacco consumption are continuous, whereas decreases in BMI occur close to the time of cancer diagnosis and may be a result of the disease and its treatment.

Although the men who were invited to participate in the Diet Cancer and Health Study were a random sample of the Danish population, the respondents differ from the general population, as married men with longer formal education were more likely to participate (Tjonneland et al, 2007), and they may represent a more health-conscious group. We were unable to control for potential confounders like physical activity, psychosocial factors and other environmental factors that may have caused changes in health behaviour. Further, as cancers were diagnosed throughout the follow-up period, the difference in time since cancer diagnosis might have affected the reporting of health behaviour; however, we conducted subanalyses of time since diagnosis to address this potential limitation. Thus, the results of this study should be generalised with care, and the findings should be interpreted with caution, as the changes in health behaviour might be due partly to changes in the measures.

Our findings nevertheless provide indications for clinicians about health behaviour changes made by male cancer survivors and might therefore be useful for planning their follow-up care. Checks for disease recurrence, late effects and psychosocial adjustment to the disease should be complemented by promotion of a healthy lifestyle.

In conclusion, this study found that, irrespective of cancer status, men significantly decrease their tobacco and alcohol consumption and BMI between baseline and follow-up. Men with cancer other than PC decreased their tobacco consumption and BMI significantly more than cancer-free men; however, the baseline levels of tobacco consumption were higher in men with cancer other than PC and then decreased to levels similar to those of cancer-free men. Still, men with cancer other than PC were more likely to quit smoking and decrease their BMI to normal weight compared with cancer-free men. These study findings should guide clinicians in planning follow-up care for cancer survivors. Future studies, with large samples, should assess health behaviour changes among men with cancers at sites other than the prostate.

\section{ACKNOWLEDGEMENTS}

This study was supported by the Danish Cancer Society.

\section{Conflict of interest}

The authors declare no conflict of interest.

\section{Ethical approval}

The Diet Cancer and Health study was approved by the regional ethical committees on human studies in Copenhagen and Aarhus and by the Danish Data Protection Agency.

\section{REFERENCES}

American Cancer Society (2010) Cancer Facts and Figures. http://www. cancerorg/acs/groups/content/@nho/documents/document/acspc-024113.pdf Aziz NM (2002) Cancer survivorship research: challenge and opportunity. J Nutr 132: 3494S-3503S

Barbeau EM, Krieger N, Soobader M (2004) Working class matters: socioeconomic disadvantage, race/ethnicity, gender and smoking in NHIS 2000. Am J Public Health 94: 269-278

Bellizzi KM, Rowland JH, Jeffery DD, McNeel T (2005) Health behaviors of cancer survivors: examining opportunities for cancer control intervention. J Clin Oncol 23: 8884-8893
Bigaard J, Spanggaard I, Thomsen BL, Overvad K, Tjonneland A (2005) Self-reported and technician-measured waist circumferences differ in middle-aged men and women. J Nutr 135: 2263-2270

Bjork C, Vinther-Larsen M, Thygesen LC, Johansen D, Gronbaek MN (2006) [Alcohol consumption by middle-aged and elderly Danes from 1987 to 2003]. Ugeskr Laeger 168: 3317-3321

Blanchard CM, Courneya KS, Stein K (2008) Cancer survivors' adherence to lifestyle behavior recommendations and associations with health-related quality of life: results from the American Cancer Society's SCS-II. J Clin Oncol 26: 2198-2204 
Broholm K (2008) Alkohol og Helbred. [Alcohol and Health]. Komiteen for Sundhedsoplysning, Sundhedstyrelsen: Copenhagen

Coups EJ, Ostroff JS (2005) A population-based estimate of the prevalence of behavioral risk factors among adult cancer survivors and noncancer controls. Prev Med 40: 702-711

Courtenay WH (2000) Constructions of masculinity and their influence on men's well-being: a theory of gender and health. Soc Sci Med 50: 1385-1401

Demark-Wahnefried W, Aziz NM, Rowland JH, Pinto BM (2005) Riding the crest of the teachable moment: promoting long-term health after the diagnosis of cancer. J Clin Oncol 23: 5814-5830

Demark-Wahnefried W, Jones LW (2008) Promoting a healthy lifestyle among cancer survivors. Hematol Oncol Clin North Am 22: 319-342viii

Demark-Wahnefried W, Peterson B, McBride C, Lipkus I, Clipp E (2000) Current health behaviors and readiness to pursue life-style changes among men and women diagnosed with early stage prostate and breast carcinomas. Cancer 88: 674-684

Demark-Wahnefried W, Rock CL, Patrick K, Byers T (2008) Lifestyle interventions to reduce cancer risk and improve outcomes. Am Fam Physician 77: 1573-1578

Eakin EG, Youlden DR, Baade PD, Lawler SP, Reeves MM, Heyworth JS, Fritschi L (2007) Health behaviors of cancer survivors: data from an Australian population-based survey. Cancer Causes Control 18: 881-894

Ekholm O, Strandberg-Larsen K, Christensen K, Gronbaek M (2008) Comparison of assessment methods for self-reported alcohol consumption in health interview surveys. Eur J Clin Nutr 62: 286-291

Gritz ER, Demark-Wahnefried W (2009) Health behaviors influence cancer survival. J Clin Oncol 27: 1930-1932

Gritz ER, Nisenbaum R, Elashoff RE, Holmes EC (1991) Smoking behavior following diagnosis in patients with stage I non-small cell lung cancer. Cancer Causes Control 2: 105-112

Groth MV, Fagt S, Stockmarr A, Matthiessen J, Biltoft-Jensen A (2009) Dimensions of socioeconomic position related to body mass index and obesity among Danish women and men. Scand J Public Health 37: 418-426

Khan N, Afaq F, Mukhtar H (2010) Lifestyle as risk factor for cancer: Evidence from human studies. Cancer Lett 293: 133-143

Kumar RJ, Barqawi A, Crawford ED (2005) Adverse events associated with hormonal therapy for prostate cancer. Rev Urol 7(Suppl 5): S37-S43
Mayer DK, Terrin NC, Menon U, Kreps GL, McCance K, Parsons SK, Mooney KH (2007) Health behaviors in cancer survivors. Oncol Nurs Forum 34: 643-651

McLaren L, Krieger N, Soobader M-J (2007) Socioeconomic status and obesity. Epidemiol Rev 29: 29-48

Mosher CE, Sloane R, Morey MC, Snyder DC, Cohen HJ, Miller PE, Demark-Wahnefried W (2009) Associations between lifestyle factors and quality of life among older long-term breast, prostate, and colorectal cancer survivors. Cancer 115: 4001-4009

Oksuzyan A, Juel K, Vaupel JW, Christensen K (2008) Men: good health and high mortality. Sex differences in health and aging. Aging Clin Exp Res 20: 91-102

Ostroff JS, Jacobsen PB, Moadel AB, Spiro RH, Shah JP, Strong EW, Kraus DH, Schantz SP (1995) Prevalence and predictors of continued tobacco use after treatment of patients with head and neck cancer. Cancer 75: 569-576

Patterson RE, Neuhouser ML, Hedderson MM, Schwartz SM, Standish LJ, Bowen DJ (2003) Changes in diet, physical activity, and supplement use among adults diagnosed with cancer. J Am Diet Assoc 103: 323-328

Pedersen CB, Gotzsche H, Moller JO, Mortensen PB (2006) The Danish Civil Registration System. A cohort of eight million persons. Dan Med Bull 53 441-449

Pinto BM, Eakin E, Maruyama NC (2000) Health behavior changes after a cancer diagnosis: what do we know and where do we go from here? Ann Behav Med 22: 38-52

Rasmussen NK (2005) Langt forre rygere blandt højtuddannede end blandt lavt uddannede. [Far fewer smokers among the high educated than among the short educated]. Statens Institut for Folkesundhed: Copenhagen

Skeie G, Hjartaker A, Braaten T, Lund E (2009) Dietary change among breast and colorectal cancer survivors and cancer-free women in the Norwegian Women and Cancer cohort study. Cancer Causes Control 20: 1955-1966

Storm HH, Michelsen EV, Clemmensen IH, Pihl J (1997) The Danish Cancer Registry - history, content, quality and use. Dan Med Bull 44: 535-539

Tjonneland A, Olsen A, Boll K, Stripp C, Christensen J, Engholm G, Overvad K (2007) Study design, exposure variables, and socioeconomic determinants of participation in Diet, Cancer and Health: a populationbased prospective cohort study of 57,053 men and women in Denmark. Scand J Public Health 35: 432-441

Umberson D, Crosnoe R, Reczek C (2010) Social relationships and health behavior across life course. Annu Rev Sociol 36: 139-157

This work is published under the standard license to publish agreement. After 12 months the work will become freely available and the license terms will switch to a Creative Commons Attribution-NonCommercial-Share Alike 3.0 Unported License. 